\title{
Synthetic curved DNA sequences can act as transcriptional activators in Escherichia coli
}

\section{Laurent Bracco, Denise Kotlarz, Annie Kolb, Stephan Diekmann ${ }^{1}$ and Henri Buc}

\author{
Institut Pasteur, Unité de Physicochimie des Macromolécules \\ Biologiques (CNRS: URA 1149), 75724 Paris Cedex 15, France and \\ 'MPI für Biophysikalishe Chemie, Postfach 2841, D-3400 Göttingen 1, \\ FRG \\ Communicated by H.Buc
}

Can a transcriptional activator known to bend DNA be functionally replaced by a sequence-directed bend in Escherichia coli? To investigate this question, a partially truncated promoter was used, deleted of its -35 region and of its CRP binding site, leaving only two Pribnow boxes as functional elements. Synthetic and naturally occurring curved DNA sequences introduced upstream from these elements could restore transcription at either one of the two natural starts. Some of these hybrid promoters turned out to be more efficient than the CRP activated wild-type gal promoter in vivo. Control experiments performed with very similar sequences devoid of any curvature produced weak promoters only. Minimal changes in the location of the centre of curvature or perturbation in the amount of curvature strongly affected the level of expression. No significant stimulation of transcription could be detected in vitro. Furthermore, both gal P1 and P2 starts could be activated in vivo but also in vitro via a properly positioned CRP binding site. This partial analogy suggests that bending induced by the cAMP-CRP complex upon binding to its site may be biologically relevant to the mechanism of transcriptional activation.

Key words: bent DNA/transcription activation

\section{Introduction}

The sequence determinants of a prokaryotic promoter, i.e. the -10 and -35 regions, and, to a lesser degree, other sequences located further upstream or downstream, dictate its kinetics of association with RNA polymerase and the efficiency of mRNA initiation (Hawley and McClure, 1983; Deutschle et al., 1986). A transcriptional activator is sometimes required to increase the synthesis of a given gene product. The catabolite activator protein (CRP) is a classical example. Complexed with cAMP, this protein binds to an upstream site in many Escherichia coli promoters to activate transcription (de Crombrugghe et al., 1984). This binding has been shown to induce a bend in the DNA (Kolb et al., 1983; Wu and Crothers, 1984). Does this bend have any functional role or is it just a non-significant consequence of CRP binding? In other words, could bent DNA per se have any effect on transcription? In the case of CRP activation, this hypothesis has already been formulated on the basis of rather indirect arguments (Wu and Crothers, 1984; Busby and Buc, 1987; Busby et al., 1987). More generally, stretches of poly (dA), known to cause DNA bending, have been reported upstream of strong promoters (Galas et al., 1985; Plaskon and Wartell, 1987) and in some cases mutation analysis or genetic selection indicated that they were important for promoter strength (Banner et al., 1983; Lamond and Travers, 1983; Bossi and Smith, 1984; Gourse et al., 1986; Bauer et al., 1988; McAllister and Achberger, 1988, 1989). To address a similar issue, we decided to carry out more drastic experiments. The E.coli gal control region was deleted of its -35 region and of its CRP binding site located at -40 . It was first shown that the whole upstream part of this sequence could be efficiently replaced by inserts containing the lactose CRP binding site. Reactivation of one of the two overlapping promoters occurred in a cAMP dependent manner and was optimal when the centre of the site was positioned with respect to the transcription start as in the original lac promoter (at -60 , i.e. two helix turns upstream from the gal CRP binding site). In a second step, similar constructs were made using various synthetic and natural DNA sequences known to be curved. Our results indicate that some of these sequences could promote transcription better than the original CRP activated wild-type promoter in vivo. This enhancement of transcription may represent an important biological role played by curved DNA sequences.

\section{Results}

We used the gal promoter of E.coli for our study. The organization of this promoter is shown in Figure la. It is actually composed of two overlapping promoters $\mathrm{P} 1$ and $\mathrm{P} 2$, both active in vivo. The -35 sequence at $\mathrm{P} 2$ is weak and the corresponding region for P1 strongly deviates from the consensus. The CRP protein, upon binding to a site centred at -41.5 bp from the P1 start, stimulates transcription in vivo, inhibiting $\mathrm{P} 2$ and activating $\mathrm{P} 1$. The presence of two Pribnow boxes, separated by $5 \mathrm{bp}$, increased our initial chances of correctly positioning potentially crucial elements with respect to these two promoters.

\section{Construction of the synthetic promoters}

In the plasmid pAA187, the gal promoters control the expression of the structural genes of the lactose operon. We used deletions which created a SmaI site and removed upstream sequences either from the $-24(\Delta 807)$ or from the $-27(\Delta 420)$ position $(+1$ being the P1 start of transcription, see Figure 1a) (Busby et al., 1983). Sequences inserted in the SmaI site of $\Delta 420$ and $\Delta 807$ are listed in Figure $1 \mathrm{~b}$. We chose the lac-CRP binding site (sequence I) to check whether both truncated gal promoters, P1 and P2, could be activated by another CRP binding site. Sequences II and III consist of tandem repeats $(\times 8)$ of a $10 \mathrm{mer}$, flanked by residual pBR322 sequences. This $10 \mathrm{mer}$ is either 4A10: 5'-GACAAAACTC-3' (which has been designed to phase at $10 \mathrm{bp}$ intervals consecutive $\mathrm{dA}$ stretches in the polymer) 


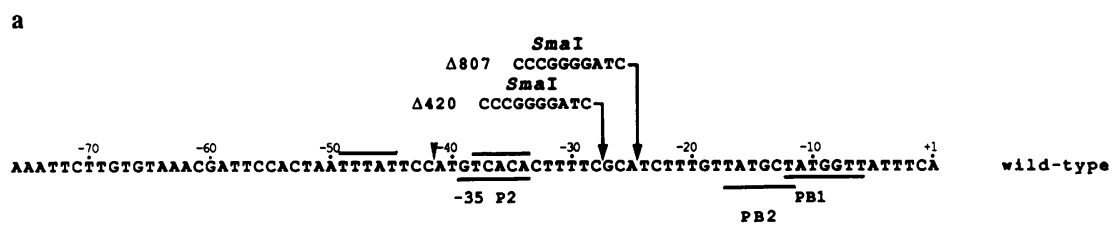

b

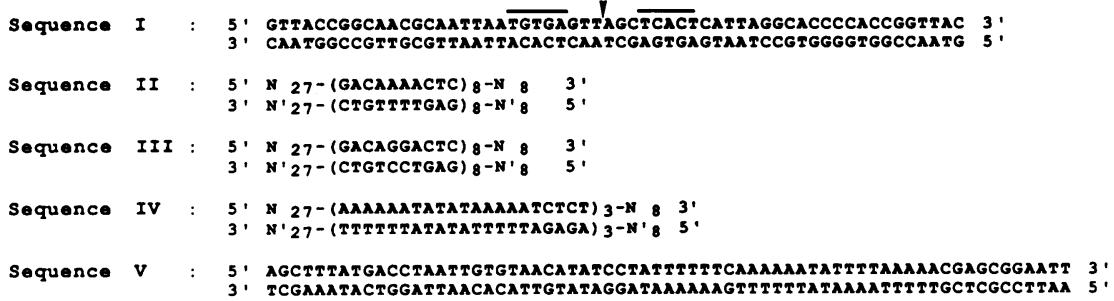

Fig. 1. (a) Sequence of the wild-type galactose promoter. The +1 position corresponds to the P1 start. The two Pribnow boxes PB1 and PB2 and the ' -35 region' are underlined. The conserved motifs of the CRP site are overlined and the pseudo-axis of symmetry symbolized by a caret. The positions of the $\Delta 420$ and $\Delta 807$ deletions are also indicated. (b) Sequences inserted in the SmaI site of pAA187- $\Delta 420$ and pAA187- $\Delta 807$. Sequence I, the CRP binding site. The conserved motifs of the CRP site are overlined and the pseudo-axis of symmetry indicated by a caret. Sequence II, $(4 \mathrm{~A} 10)_{8}$ polymer flanked by residual pBR322 sequences $\left(\mathrm{N}_{27}\right.$ and $\left.\mathrm{N}_{8}\right)$. Sequence III, (1A10) 8 polymer flanked by residual pBR322 sequences ( $\mathrm{N}_{27}$ and $\left.\mathrm{N}_{8}\right)$. Sequence IV, the $5 \mathrm{~A} / 6 \mathrm{~A}$ Ulanovsky sequence flanked by residual pBR322 sequences $\left(\mathrm{N}_{27}\right.$ and $\left.\mathrm{N}_{8}\right)$. Sequence V, the upstream $S p o$ VG element.

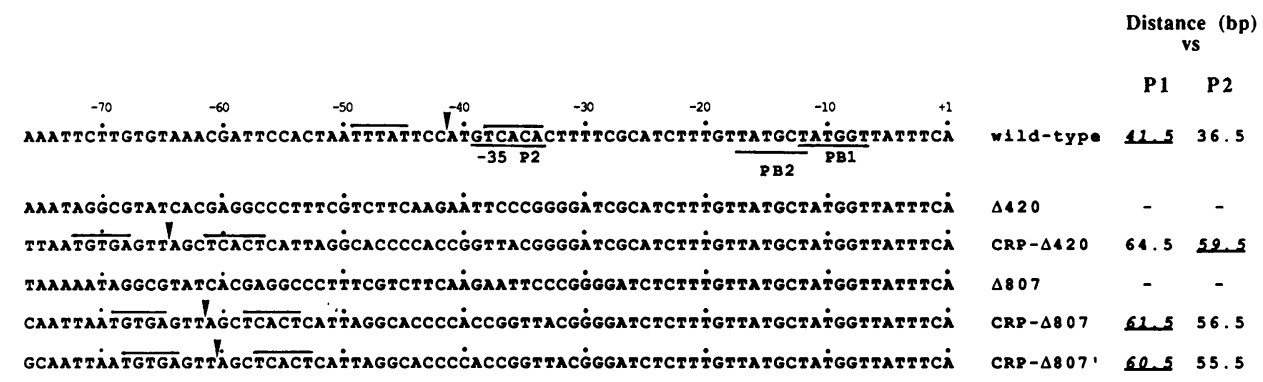

Fig. 2. Sequence of the starting deletion promoters and of the lac-CRP hybrid promoters. The conserved motifs of the CRP site are overlined and the pseudo-axis of symmetry indicated by a caret. The distance (bp) corresponds to the interval between the centre of the CRP binding site to the P1 and P2 starts.

or 1A10: 5'-GACAGGACTC-3' (which serves as a negative control). Sequence II is strongly curved as detected by its abnormal migration within a polyacrylamide gel matrix contrary to sequence III which showed no sign of curvature (Diekmann, 1987). Sequence IV is a tandem repeat $(\times 3)$ of $21 \mathrm{bp}$ studied by Ulanovsky and colleagues which contains alternating stretches of 5 and $6 \mathrm{dAs}$ at $10.5 \mathrm{bp}$ intervals (Ulanovsky et al., 1986). Measurements of k factors (ratio of the apparent length of a DNA fragment as deduced from its mobility to its actual length) indicated a more intense curvature for this sequence than for sequence II (Diekmann, 1987). Sequence V represents an AT rich region found upstream of the SpoVG promoter in Bacillus subtilis, which has been shown to be an important determinant of this promoter and to migrate abnormally in electrophoresis (Banner et al., 1983). This sequence was only inserted in $\Delta 420$. The blunt end cloning procedure was used to generate plasmids with sequences inserted in the two possible orientations.

\section{In vivo strength of the hybrid gal promoters}

The lac-CRP constructs. Three synthetic promoters were characterized for this study. The corresponding sequences from +1 to -76 are shown in Figure 2. Two of these promoters, CRP- $\Delta 807, \mathrm{CRP}-\Delta 420$ were expected from our
Table I. $\beta$-Galactosidase activities associated with the lac-CRP hybrid promoters

\begin{tabular}{|c|c|c|c|c|}
\hline & $\begin{array}{l}\beta \text {-Galactosidase } \\
\text { (-cAMP) }\end{array}$ & $\begin{array}{l}\beta \text {-Galactosidase } \\
(+2 \text { mM cAMP })\end{array}$ & Activation $^{\mathrm{a}}$ & Distance $^{b}$ \\
\hline gal wild-type & 1240 & 4700 & 3.8 & $41.5(\mathrm{P} 1)$ \\
\hline$\Delta 420$ & 520 & 310 & 0.6 & - \\
\hline$\Delta 807$ & 820 & 490 & 0.6 & - \\
\hline CRP- $\Delta 807$ & 1120 & 4340 & 4.0 & $61.5(\mathrm{P} 1)$ \\
\hline$C R P-\Delta 807^{\prime}$ & 1035 & 5520 & 5.3 & $60.5(\mathrm{P} 1)$ \\
\hline CRP- $\Delta 420$ & 420 & 2530 & 6.0 & $59.5(\mathrm{P} 2)$ \\
\hline
\end{tabular}

${ }^{a}$ Defined as the ratio of the $\beta$-galactosidase units in the presence and the absence of cAMP.

${ }^{b}$ Defined as the interval between the centre of the CRP binding site and the transcription start of the promoter indicated in parenthesis.

original design. The third promoter, CRP- $\Delta 807^{\prime}$ is a mutant of CRP- $\Delta 807$ having a 1 bp deletion at position -30 (part of the SmaI cloning site). These plasmids were used to transform a $\Delta$ lac cya strain. $\beta$-Galactosidase assays were performed in the absence or presence of cAMP in the growth medium to measure the in vivo strength of these promoters as well as the extent of activation by the cAMP-CRP complex (Table I). These constructs could be activated by the cAMP-CRP complex by roughly the same factor (4-6 


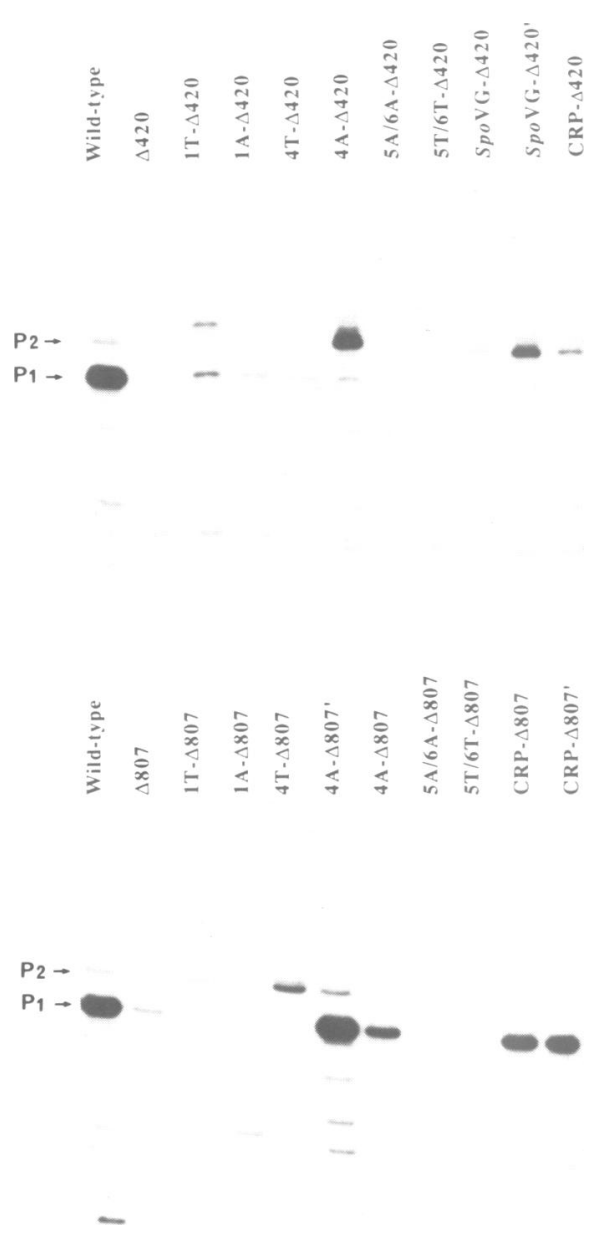

Fig. 3. Analysis of the in vivo transcripts: origins and quantitation of the mRNA products. The bands corresponding to a P1 or P2 start of transcription are indicated. See Materials and methods for the reaction conditions.

times). The start and the amount of the mRNA transcripts originating from these hybrid promoters were then determined by a primer extension method using total RNA synthesized in vivo in a parent cya ${ }^{+}$strain, M182recA (see Materials and methods for genotype) (Figure 3). For each construct, one or two main bands are observed corresponding either to a P1 or to a P2 start. CRP- $\Delta 807$ and CRP- $\Delta 807^{\prime}$ corresponded excusively to a P1 start whereas P2 was utilized in CRP- $\triangle 420$. Thus, both truncated promoters could be activated by the cAMP - CRP complex through a properly positioned binding site (59.5-61.5 bp instead of 41.5 in the wild-type P1 gal promoter).

The bent DNA sequences. The sequences of the hybrid promoters constructed with these curved DNA fragments are listed in Figure 4. The corresponding plasmids were used to transform M182 recA. Phenotypes and $\beta$-galactosidase activities associated with each construct are indicated in Table II. The plasmids carrying the deleted promoters, $\Delta 420$ and $\Delta 807$, gave a $\mathrm{Lac}^{-}$phenotype of MacConkey lactose indicator plates, whereas the wild-type gal promoter corresponded to a $\mathrm{Lac}^{+}$phenotype. $4 \mathrm{~A}-\Delta 807$ and $4 \mathrm{~A}-\Delta 420$ strongly promoted $\beta$-galactosidase expression ( 91 and $142 \%$ respectively of the wild-type activity). Their corresponding controls $1 \mathrm{~A}-\Delta 807$ and $1 \mathrm{~A}-\Delta 420$ produced weak promoters. The two other promoters originating from the $4 \mathrm{~A} 10$ motifs,
4T- $\Delta 420$ and 4T- $\Delta 807$, gave intermediate levels of $\beta$-galactosidase (42 and $29 \%$ ). Nevertheless, $4 \mathrm{~T}-\Delta 807$ was five times more active than its control 1T- $\Delta 807$, whereas $4 \mathrm{~T}-\Delta 420$ and $1 \mathrm{~T}-\Delta 420$ gave identical results. Interestingly, the Ulanovsky sequence in each of the four plasmids, $5 \mathrm{~A} / 6 \mathrm{~A}$ $\Delta 420,5 \mathrm{~T} / 6 \mathrm{~T}-\Delta 420,5 \mathrm{~A} / 6 \mathrm{~A}-\Delta 807$ and $5 \mathrm{~T} / 6 \mathrm{~T}-\Delta 807$ were totally inefficient as upstream promoter elements $(\sim 10 \%$ of the wild-type activity). Similarly, SpoVG- $\Delta 420$ could not restore a $\mathrm{Lac}^{+}$phenotype (20\% of the wild-type activity). Thus, a subset of the curved DNA sequences appeared to be responsible for a strong promoter activity. The origin and the amount of the transcripts were again determined by the primer extension method (Figure 3). The relative intensities of the extended chains were in qualitative agreement with the results of the $\beta$-galactosidase assay considering the three times better translational efficiency of the mRNA originating at $\mathrm{P} 2$ versus P1 (Queen and Rosenberg, 1981; Dreyfus et al., 1985 ). Since the plasmid copy number did not appreciably change among all the constructs, we attributed the observed stimulation by some of the curved sequences to a direct transcriptional effect. Both promoters could then also be specifically and strongly activated by curved DNA sequences: $\mathrm{P} 1$ in $4 \mathrm{~A}-\Delta 807, \mathrm{P} 2$ in $4 \mathrm{~A}-\Delta 420$ and to a lesser extent in $4 \mathrm{~T}-\Delta 807$.

The proper location of the bent DNA sequences is a highly sensitive parameter for this upstream activation We were able to isolate two mutants, $4 \mathrm{~A}-\Delta 807^{\prime}$ and SpoVG$\Delta 420^{\prime}$, in which a single base pair deletion was fortuitously created at the SmaI junction (see Figure 4). The effect of this deletion on the in vivo strength of these two promoters was remarkable, increasing their efficiency by a factor of 3-4.5 (Table III). 4A- $\Delta 807^{\prime}$ now corresponded to a promoter almost three times as active as the CRP induced wildtype gal promoter and SpoVG- $\Delta 420^{\prime}$ was nearly as efficient as wild-type. The mRNA analysis revealed that $4 \mathrm{~A}-\Delta 807^{\prime}$ was still utilizing gal P1 and that SpoVG- $\Delta 420^{\prime}$ originated transcription at P2 (Figure 3).

\section{Effect of the DNA superhelicity in vivo on the activation by curved sequences}

The in vivo strengths of the wild-type and some hybrid promoters were tested in a top ${ }^{-}$and a gyr $^{-}$genetic background by performing $\beta$-galactosidase assays (Table IV).

Activation by the curved sequences consisting of the $4 \mathrm{~A} 10$ polymer (in $4 \mathrm{~A}-\Delta 807$ and $4 \mathrm{~A}-\Delta 807^{\prime}$ ) and of the SpoVG upstream element (in $S p o$ VG- $\Delta 420$ and $S p o$ VG- $\Delta 420^{\prime}$ ) was observed in the three different genetic backgrounds. In the gyr $^{-}$allele, no significant difference in the amount of activation was observed. With the top ${ }^{-}$allele, the extent of the stimulation was significantly modulated by the degree of superhelicity only in the case of SpoVG- $\Delta 420$ and SpoVG$\Delta 420^{\prime}$, where an increase in negative supercoiling weakened the activation by $60 \%$.

\section{The activation of transcription by the $(4 A 10)_{8}$ motif could not be reproduced in vitro}

We attempted to reproduce our in vivo data, using linear DNA templates in vitro. Significant activation of run-off transcription starting at the expected origin was observed for CRP- $\Delta 420$ and CRP- $\Delta 807$. However, no stimulation of transcription could be detected with $4 \mathrm{~A}-\Delta 420$ and $4 \mathrm{~A}-\Delta 807^{\prime}$ 


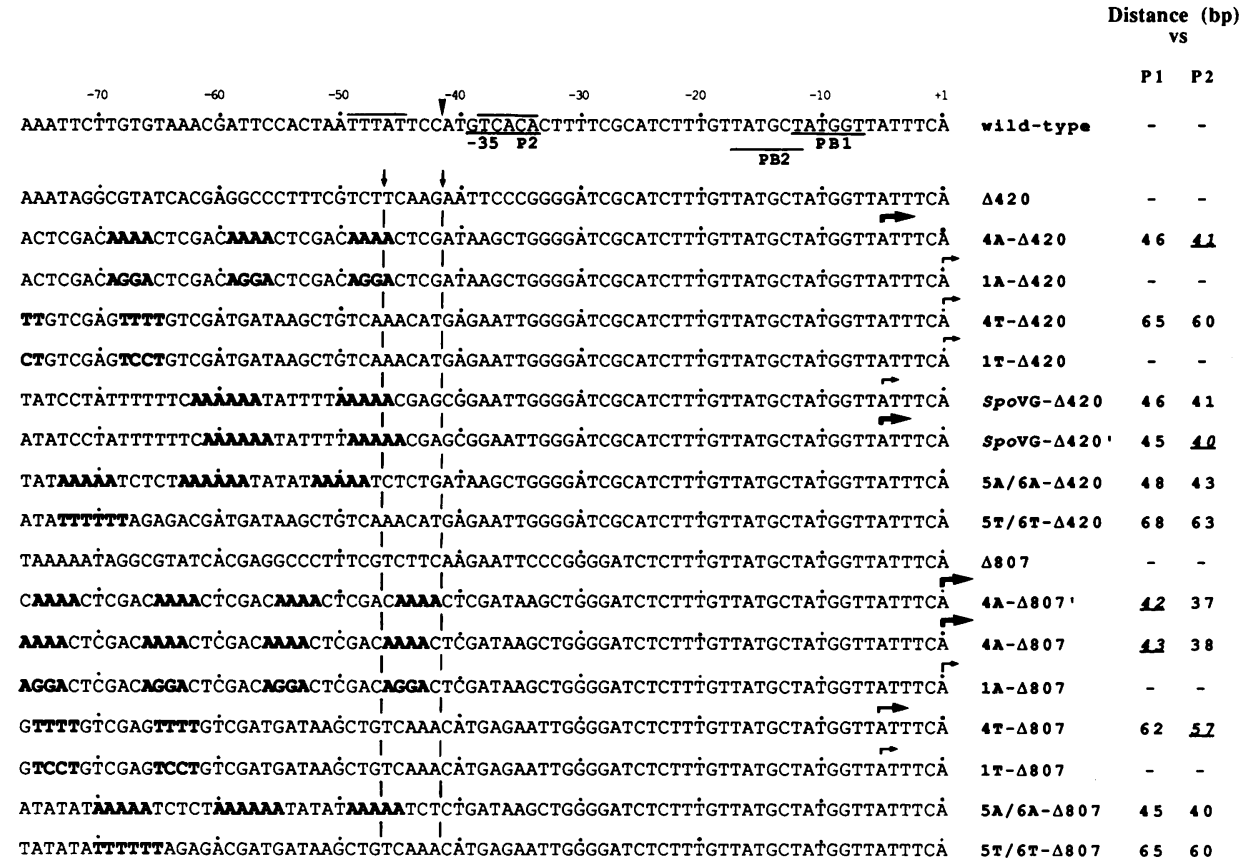

Fig. 4. Sequence of the bent DNA hybrid promoters and of their controls. The important elements (dA or dT stretches and homologous control sequences) are in bold face. The starts of transcription have been materialized by arrows of various sizes indicative of the strength of the promoter The -41.5 and -46.5 positions are indicated by vertical arrows. The distance (bp) corresponds to the interval between the end of the proximal dA or dT stretch to the P1 and P2 starts. The relevant distances in the activated constructs in the last two columns have been italicized and underlined.

with respect to their controls, $1 \mathrm{~A}-\Delta 420$ and $1 \mathrm{~A}-\Delta 807$. In addition, all transcripts originated from $\mathrm{P} 2$ whereas $4 \mathrm{~A}$ $\Delta 807$ ' corresponded to $\mathrm{P1}$ in vivo (data not shown). Similar results were obtained when purified negatively supercoiled plasmid DNA was used in place of linear DNA. $4 \mathrm{~A}-\Delta 807^{\prime}$ was chosen since two parameters, the amount and the origin of the transcripts were different in vivo and in vitro. 4A$\Delta 807^{\prime}$ and $1 \mathrm{~A}-\Delta 807$ produced comparable amounts of transcripts (Figure 5, cf. lane 2 with lane 4 or lane 3 with lane 5). $4 \mathrm{~A}-\Delta 807^{\prime}$ appeared slightly stronger than $1 \mathrm{~A}-\Delta 807$ but this difference was minimal compared with the activation observed in vivo. In addition, the main in vitro start was still $\mathrm{P} 2$ in contrast to the in vivo results.

\section{Is a DNA binding protein involved in the activation by curved sequences?}

Activation could also have resulted from the action of a DNA binding protein facilitating the positioning of RNA polymerase on a promoter containing a curved upstream region. The first candidate was the cAMP-CRP complex itself which could have interacted directly with RNA polymerase at these loci. This hypothesis was discarded by comparing the level of activation observed for the $4 \mathrm{~A}-\Delta 807^{\prime}$ constructs (with respect to $1 \mathrm{~A}-\Delta 807$ ) in a $\mathrm{crp}^{-}$or cya ${ }^{-}$ background (in the presence or absence of cAMP). In those strains $4 \mathrm{~A}-\Delta 807^{\prime}$ remained a strong promoter insensitive to the presence of a functional cAMP-CRP complex inside the cell. 1A- $\triangle 807$ remained uniformly weak (data not shown). We also considered the possible involvement of IHF in recognition of the bent motifs. The activation in vivo by the 4A10 sequences was maintained in E.coli strain 02014 (hip) and purified IHF did not influence the in vitro transcription either (data not shown).
Table II. Phenotype, $\beta$-galactosidase activities and in vivo origins of transcription associated with the bent DNA hybrid promoters and their controls

\begin{tabular}{llll}
\hline & Phenotype $^{\mathrm{a}}$ & $\begin{array}{l}\beta \text {-Galactosidase } \\
\text { activity }\end{array}$ & $\begin{array}{l}\text { Origin of } \\
\text { transcription }\end{array}$ \\
\hline Wild type & $\mathrm{Lac}^{+}$ & 100 & $\mathrm{P} 1$ \\
$\Delta 420$ & $\mathrm{Lac}^{-}$ & 7 & $\mathrm{P} 1$ \\
4A- $\Delta 420$ & $\mathrm{Lac}^{+}$ & 142 & $\mathrm{P} 2$ \\
1A- $\Delta 420$ & $\mathrm{Lac}^{+/-}$ & 23 & $\mathrm{P} 1$ \\
4T- $\Delta 420$ & $\mathrm{Lac}^{+/}$ & 29 & $\mathrm{P} 1$ \\
1T- $\Delta 420$ & $\mathrm{Lac}^{+/}$ & 28 & $\mathrm{P} 1$ \\
5A/6A- $\Delta 420$ & $\mathrm{Lac}^{-}$ & 12 & $\mathrm{P} 1$ \\
5T/6T- $\Delta 420$ & $\mathrm{Lac}^{-}$ & 13 & $\mathrm{P} 1 / \mathrm{P} 2$ \\
SpoVG- $\Delta 420$ & $\mathrm{Lac}^{+/}$ & 20 & $\mathrm{P}$ \\
& & & \\
$\Delta 807$ & $\mathrm{Lac}^{-}$ & 12 & $\mathrm{P} 1$ \\
4A- $\Delta 807$ & $\mathrm{Lac}^{+}$ & 91 & $\mathrm{P} 1$ \\
1A- $\Delta 807$ & $\mathrm{Lac}^{-}$ & 14 & $\mathrm{P} 1$ \\
4T- $\Delta 807$ & $\mathrm{Lac}^{+}$ & 42 & $\mathrm{P} 2$ \\
1T- $\Delta 807$ & $\mathrm{Lac}^{-}$ & 9 & $\mathrm{P} 2$ \\
5A/6A- $\Delta 807$ & $\mathrm{Lac}^{-}$ & 8 & $\mathrm{P} 2$ \\
5T/6T $\Delta 807$ & $\mathrm{Lac}^{-}$ & 7 & $\mathrm{P} 2$ \\
\hline
\end{tabular}

${ }^{a}$ Observed on MacConkey lactose medium.

${ }^{b}$ Expressed as percentage of the $\beta$-galactosidase activity measured in the wild-type strain (2800 units).

${ }^{\mathrm{c}} \mathrm{cf}$. Figure 3.

Other experiments were performed in parallel in vitro by comparing the relative affinity of several DNA binding proteins for curved versus straight sequences. Gel retardation assays showed that the E.coli DNA binding protein $\mathrm{H1}$ (Spassky et al. , 1984) had a better affinity for the $(4 \mathrm{~A} 10)_{8}$ sequence than for the $(1 \mathrm{~A} 10)_{8}$ sequence (Figure 6). To a 
Table III. Influence of a 1 bp deletion on the in vivo promoter strength of two bent DNA hybrid promoters

\begin{tabular}{llll}
\hline Promoter & Phenotype & $\begin{array}{l}\beta \text {-Galactosidase } \\
\text { activity }\end{array}$ & $\begin{array}{l}\text { Origin of } \\
\text { transcription }\end{array}$ \\
\hline Wild-type & Lac $^{+}$ & 100 & $\mathrm{P} 1$ \\
4A- $\Delta 807$ & $\mathrm{Lac}^{+}$ & 91 & $\mathrm{P} 1$ \\
4A- $\Delta 807^{\prime}$ & $\mathrm{Lac}^{+}$ & 270 & $\mathrm{P} 1$ \\
SpoVG- $\Delta 420$ & $\mathrm{Lac}^{-}$ & 20 & $\mathrm{P} 2$ \\
SpoVG- $\Delta 420^{\prime}$ & Lac $^{+}$ & 92 & $\mathrm{P} 2$ \\
\hline
\end{tabular}

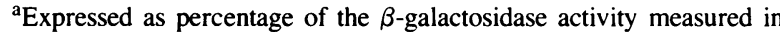
the wild-type strain (2800 units).

Table IV. Influence of the superhelicity on the in vivo activation by the $4 \mathrm{~A} 10$ polymer

\begin{tabular}{lclc}
\hline & T13recA & $\begin{array}{l}\text { T23recA } \\
\text { top }\end{array}$ & $\begin{array}{l}\text { T33recA } \\
\left(\text { gyr }^{-}\right)\end{array}$ \\
\hline Wild-type & $100^{\mathrm{a}}$ & $100^{\mathrm{b}}$ & $100^{\mathrm{c}}$ \\
4A- $\Delta 807^{\prime}$ & 350 & 265 & 360 \\
4A- $\Delta 807$ & 115 & 98 & 118 \\
lA- $\Delta 807$ & 25 & 23 & 26 \\
$\Delta 807$ & 24 & 19 & 18 \\
SpoVG- $\Delta 420$ & 41 & 27 & 37 \\
SpoVG- $\Delta 420^{\prime}$ & 105 & 62 & 117 \\
\hline
\end{tabular}

a.b.c Expressed as percentage of units for the wild-type promoter in a given strain

${ }^{a} 100$ is equivalent to 3200 units for wild-type.

${ }^{b} 100$ is equivalent to 2400 units for wild-type.

c 100 is equivalent to 3500 units for wild-type.
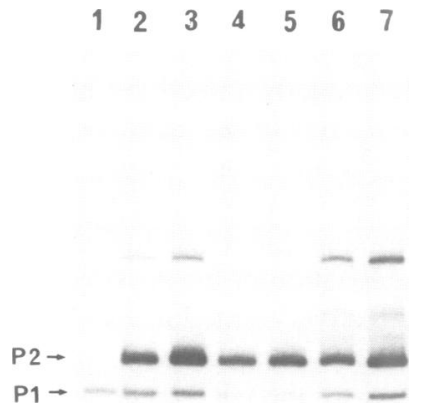

Fig. 5. In vitro transcription on purified plasmid DNA templates. The $\mathrm{P} 1$ and $\mathrm{P} 2$ starts of transcription are indicated. 1, in vivo start of transcription from $4 \mathrm{~A}-\Delta 807^{\prime}$ (inserted to emphasize the difference between the in vivo and the in vitro starts for $4 \mathrm{~A}-\Delta 807^{\prime}$. No comparison in band intensities should be made). 2: $4 \mathrm{~A}-\Delta 807^{\prime}$, at $37^{\circ} \mathrm{C}$ for $10 \mathrm{~min}$. 3: $4 \mathrm{~A}-\Delta 807^{\prime}$, at $37^{\circ} \mathrm{C}$ for $30 \mathrm{~min}$. 4: $1 \mathrm{~A}-\Delta 807$, at $37^{\circ} \mathrm{C}$ for $10 \mathrm{~min}$. 5: $1 \mathrm{~A}-\Delta 807$, at $37^{\circ} \mathrm{C}$ for $30 \mathrm{~min}$. 6: $4 \mathrm{~A}-\Delta 807^{\prime}$, at $16^{\circ} \mathrm{C}$ for $10 \mathrm{~min}$. 7: $4 \mathrm{~A}-\Delta 807^{\prime}$, at $16^{\circ} \mathrm{C}$ for $30 \mathrm{~min}$.

lesser extent, it also seemed to be true for the histone-like protein HU (Drlica and Rouvière-Yaniv, 1987, J.RouvièreYaniv, personal communication) and RNA polymerase.
H 1
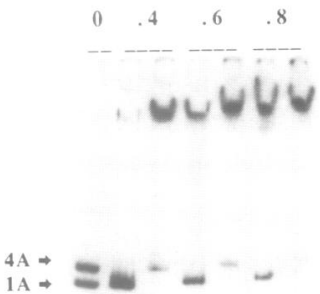

POL

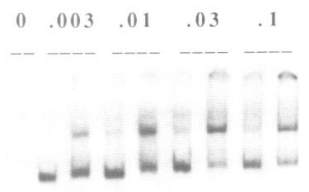

$4 \mathrm{~A} \Rightarrow$

Fig. 6. Comparative gel retardation analysis showing the binding of $\mathrm{H} 1$ and RNA polymerase to $113 \mathrm{bp}$ EcoRI-HindIII fragments (Diekmann, 1987), containing eight decamers of either the curved sequence (fragment $4 \mathrm{~A}$ ) or the control sequence (fragment $1 \mathrm{~A}$ ) as indicated in Materials and methods. In lane $\mathbf{0}$, an equimolar mixture of 4A and 1A fragments was loaded with no protein. The protein concentration is given in $\mu \mathrm{M}$. At each protein concentration, the first lane corresponds to the $1 \mathrm{~A} 10$ polymer and the second lane to the $4 \mathrm{~A} 10$ polymer.

However, the addition of $\mathrm{Hl}$ or $\mathrm{HU}$ to the transcription reaction using plasmid DNA template neither activated the 4A$\Delta 807^{\prime}$ promoter with respect to the $1 \mathrm{~A}-\Delta 807$ nor did it induce any shift towards a preferred utilization of the P1 promoter.

\section{Discussion}

The results obtained with the lac-CRP hybrid constructs indicate that both gal promoters when deleted upstream of position -24 or -27 can be reactivated in a cAMP dependent manner by the insertion, at a proper distance from the transcription start, of the lactose CRP binding site. The -35 regions show no significant homology with the consensus sequences, suggesting that no element other than a Pribnow box and a good binding site for the activating complex is required to make those promoters functional in the presence of cAMP.

In the wild-type gal control region the centre of the binding site for the activating complex is located at -41.5 from the $\mathrm{P} 1$ promoter which is activated. In CRP- $\Delta 807$, the same promoter is now turned on by a site inserted at the same distance as in the original lac background (61.5 bp). Hence, swapping between two CRP sites is possible in the gal P1 background, and activation proceeds as well, whether the distance is 41.5 or $61.5 \mathrm{bp}$. The results obtained with CRP$\Delta 420$ (P2 activated) and CRP- $\Delta 807^{\prime}$ (P1 activated) indicate that deviation from the $61.5 \mathrm{bp}$ spacing could be accommodated by the nucleoprotein assembly and still lead to promoter activation (the corresponding distances to the start 
sites are 59.5 and $60.5 \mathrm{bp}$ ). In the case of the lac promoter, two reports (Mandecki and Caruthers, 1984; Straney et al., 1989) indicated that the insertion of $5 \mathrm{bp}$, i.e. half a turn of B-DNA helix, between the CRP binding site and the -35 region prevented CRP activation. This activation was partially restored when $11 \mathrm{bp}$ replaced the $5 \mathrm{bp}$ insertion. Deletions and insertions of 1 or $2 \mathrm{bp}$ also modulated the activation of CRP (Mandecki and Caruthers, 1984). A more extensive study of our hybrid constructs will be reported elsewhere.

We have demonstrated that naturally bent sequences could activate transcription in vivo in place of a CRP site when positioned upstream of the same gal Pribnow boxes. The most striking example, $4 \mathrm{~A}-\Delta 807^{\prime}$, was 20 times more efficient than its corresponding negative control, $1 \mathrm{~A}-\Delta 807$. This activation could affect both promoters, gal P1 and gal P2. The same sequence (II, see Figure 2) in one of the two possible orientations activated $\mathrm{P} 1$ in the promoter $4 \mathrm{~A}-\Delta 807$ and activated $\mathrm{P} 2$ when moved upstream by $3 \mathrm{bp}$ in $4 \mathrm{~A}-\Delta 420$. In both cases, replacement of sequence II by sequence III (cf. results of $1 \mathrm{~A}-\Delta 420$ and $1 \mathrm{~A}-\Delta 807$ in Table II) led to low levels of $\beta$-galactosidase activities, comparable to the ones observed in the starting deletions, and originating from the same promoter, P1. Thus the shift from P1 to P2 observed in $4 \mathrm{~A}-\Delta 420$, as well as the increase in expression, are indeed due to the insertion of the phased $4 \mathrm{~A}$ sequences. The results obtained with the $1 \mathrm{~A}-\Delta 420$ control rule out, in particular, the objection that perhaps the -35 region of $P 2$, also shared by $4 \mathrm{~A}-\Delta 420$, could be more efficient than the corresponding -35 region of P1. None of these sequences show good homology with consensus hexamers, but in view of recent results indicating that such non-homologous -35 sequences could produce very efficient promoters (Horwitz and Loeb, 1988; Jacquet and Ehrlich, 1985), it was essential to show that no element present in the $1 \mathrm{~A}$ sequences led to significant promoter activity. Finally, sequence II can be inserted in the opposite orientation placing the $\mathrm{dA}$ stretches on the other strand, and still lead to a significant activation (cf. 4T- $\Delta 807$ ). In general, the gal control region appears very suitable for such replacements, as also shown recently by Chan and Busby (1989).

It is possible to score the promoter strength of P1 and P2 in the various constructs as a function of the distance of the first curved motif to the two starts, taking into account not only the positive outcomes but also the negative results (no significant activity). As shown in Figure 4, there is a narrow window of spacings leading to activity when distances, taken from the 3 ' end of the dA stretch closest to the transcription starts are $<40-43 \mathrm{bp}>$. In the most active promoter, 4A$\Delta 807^{\prime}$, this interval is $42 \mathrm{bp}$. However, three constructs lie in the corresponding window and fail to yield marked stimulation, SpoVG- $\Delta 420,5 \mathrm{~A} / 6 \mathrm{~A}-\Delta 420$ and $5 \mathrm{~A} / 6 \mathrm{~A}-\Delta 807$ (all with respect to $\mathrm{P} 2$ ). None of the constructs derived from the Ulanovsky sequence yields an active promoter. The stronger curvature observed with these upstream elements may be detrimental to the activation. Another almost equivalent way to look at the problem is to position the centre of the gal P1 CRP site (at -41.5) or of the CRP site which would activate gal P2 (at -46.5 ) with respect to the bent sequences which stimulate a given promoter. This is done in Figure 4. One finds that in the activated constructs, the $3^{\prime}$ end of the first A stretch, which has been associated with a more pronounced bend in the so-called junction model (KoO and Crothers, 1988; Koo et al., 1986) comes very close to this position. In their analysis of promoter sequences from E.coli, Galas et al. (1985) found a significant subset of promoters possessing an $A_{n}$ sequence centred around $-44 \mathrm{bp}$, which might fulfill a similar function. Plaskon and Wartell (1987) have independently noticed that such tracts were often phased. In B. subtilis, McAllister and Achberger (1989) have shown that the phasing between the -35 region and poly $(\mathrm{dA})$ stretches known to act as positive upstream elements was essential to promoter activity: 11 and $21 \mathrm{bp}$ insertions (i.e. one and two helical turns of B-DNA) between these two regions only slightly affected promoter efficiency, while a $15 \mathrm{bp}$ insertion was very detrimental to promoter activity. RNA polymerase binding experiments suggested that the curvature associated with these upstream elements may allow additional polymerase-DNA contacts which would be responsible for the observed effects on promoter function. Some of our results could be interpreted in the same way. We note that the $3^{\prime}$ proximal dT in the promoter 4T$\Delta 807$ is located $57 \mathrm{bp}$ away from the activated start, i.e. 15 bp upstream (or 1.5 helical turn of B-DNA) from the $3^{\prime}$ position of the 4A sequences which activate the $4 \mathrm{~A}-\Delta 807^{\prime}$ promoter (cf. underlined numbers in the two last columns of Figure 4). When dA stretches have been replaced by dT stretches, we would have precisely expected such a correlation if the primary determinant for activation was the rotational orientation of the curved DNA sequence.

The proper positioning of bent upstream elements is of the upmost importance for promoter function. A 1 bp insertion completely destroyed the ability of the SpoVG sequence to activate transcription and reduced the ability of the 4A10 motif to act as an upstream promoter element (see Table III; Figure 3). In the same line of reasoning, we note that negative superhelicity sometimes modifies the relative activation in vivo by curved sequences suggesting that untwisting affects phasing. Thus, there is a similarity between this activation and the activation by the CRP protein: both $\mathrm{P} 1$ and $\mathrm{P} 2$ promoters can be stimulated in vivo in both instances and the location of the $A_{n}$ stretch and of the CRP binding site effectively modulates this phenomenon. However, this analogy stopped when in vitro experiments were performed. With the CRP constructs, the amount and start of the transcripts were in total correspondence with the in vivo results whereas these were not matched with the hybrid promoters containing the bent DNA sequences.

Several laboratories have studied the influence of naturally occurring $\mathrm{A}$ or $\mathrm{T}$ stretches positioned upstream of -35 regions on promoter efficiency. None of the activation effects were as large as the ones reported here. In many reports, only in vivo experiments involving mutations and deletions have been performed (Lamond and Travers, 1983; Gourse et al., 1986) but, in three instances, in vitro studies supported the in vivo data. Bossi and Smith (1984) reported a 2-fold activation of the his tRNA promoter by upstream bent sequences in Salmonella typhimurium. A 3 bp deletion destroyed the curvature and the activation as well. This result could be reproduced in vitro using E. coli RNA polymerase. Another study (Banner et al., 1983) demonstrated the positive effect, in vivo, of bent upstream sequences on the two SpoVG promoters P1 and P2 in B.subtilis. Run-off experiments in vitro on linear templates using a mixture of the $\sigma^{37}$ and $\sigma^{32}$ factors associated to core RNA polymerase confirmed their in vivo data. As mentioned above, McAllister 
Table V. Strains of E.coli K12

\begin{tabular}{|c|c|c|c|}
\hline Name & Relevant genotype & Origin & Reference \\
\hline M182 & $\begin{array}{l}\text { DlacX74 galK galU } \\
\text { rpsL }\end{array}$ & S.Busby & $\begin{array}{l}\text { Casadaban and } \\
\text { Cohen (1979) }\end{array}$ \\
\hline $\mathrm{T} 13$ & M182 pyrF & this work & \\
\hline T14 & $\begin{array}{l}\text { M182 pyrF } \Delta c y a 854 \\
\text { ilv::Tn5 }\end{array}$ & this work & $\begin{array}{l}\text { Ebright } \text { et al. } \\
\text { (1984) for the } \\
\Delta \text { cya } 854 \text { character }\end{array}$ \\
\hline T23 & M182 pyrF top 10 & this work & $\begin{array}{l}\text { Sternglanz et al. } \\
\text { (1981) }\end{array}$ \\
\hline T33 & $\begin{array}{l}\text { M182 pyrF gyrB226 } \\
\text { tnaA::Tn1O }\end{array}$ & this work & Drlica et al. (1986) \\
\hline GC2226 & $\begin{array}{l}\text { Hfr KL16 recA } \\
\text { srl::Tn10 }\end{array}$ & C.Wandersman & $\begin{array}{l}\text { Wandersman et al. } \\
\text { (1980) }\end{array}$ \\
\hline MCL30 & $\begin{array}{l}\text { Hfr PO45 thi-1 } \\
\Delta(\text { srl-recA } 306:: \operatorname{Tn} 10\end{array}$ & $\begin{array}{l}\text { M.Lorence via } \\
\text { A.Pugsley }\end{array}$ & $\begin{array}{l}\text { Lorence and Rupert } \\
\text { (1983) }\end{array}$ \\
\hline 02014 & $\begin{array}{l}\text { F-araD139 lac strA } \\
\text { supF trp::Tn } 10 \\
\text { hip::cat }\end{array}$ & R.Weisberg & \\
\hline
\end{tabular}

and Achberger (1988) have investigated the influence of three phased poly (dA) stretches on two B. subtilis promoters. In vivo, such sequences activated one of the two promoters but weakened the second one. These effects could be somewhat qualitatively reproduced in vitro using the major $\sigma^{43}$ B. subtilis RNA polymerase. In the case where the dA stretches acted as positive elements, the use of supercoiled templates in vitro partially compensated for the lack of these upstream sequences.

Contrary to these reports, and in spite of numerous attempts and changes in experimental conditions, we could not find an in vitro system where the in vivo results could be reproduced using E.coli $\sigma^{70}$ RNA polymerase and linear or supercoiled templates. We can invoke four explanations for this negative result.

First, a very specific range of superhelical density of the template could be required to lead to promoter activation. Cases are indeed known where the strength of a given promoter is increased in a rather narrow range of negative supercoiling (cf. e.g. Brahms et al., 1985). We are pursuing along these lines in vitro experiments.

Second, it is still possible but less likely that the enzyme operating on these templates in vivo is not the major form of RNA polymerase. Preliminary in vivo experiments disfavour a specific recognition of these sequences by $\sigma^{32}$, the heat shock sigma subunit, but other minor forms have not been investigated.

Third, auxiliary factors present in the E.coli chromoid could bind to these upstream sequences and be essential for the proper positioning of RNA polymerase (cf. better affinity shown above of factor $\mathrm{H} 1$ for the $4 \mathrm{~A} 10$ sequence as compared with 1A10). They could act directly as activators, or release a prior inhibition due to improper RNA polymerase positioning. In the above mentioned studies by Bosssi, by Banner and by McAllister, activation could be reproduced in vitro without additional factors. It is not unlikely that, in our case, both a change in negative superhelicity and the addition of at least one factor are required to observe a significant activation in vitro.

Fourth, the situation could be even more complex if the bent sequences prevented the formation of a chromoid structure within the cell which could facilitate the access to the promoter. In yeast, two reports (Russell et al., 1983; Chen et al., 1987) indicated that poly(dA-dT) could act as upstream transcriptional activator and that the probable reason for this effect was a displacement of the chromatin structure around the promoter. Indeed, this activation could not be reproduced in vitro either. More recently, A.P.Wolffe and H.Drew (unpublished data) have reconstituted chromatin on closely related DNA fragments containing curved sequences and found that the positioning of nucleosomes was strongly affecting transcription.

Whatever the explanation is, we want to emphasize that the effects reported here are very large and that they afford the possibility of a genetic analysis of the partners involved. Goodman and Nash (1989) have recently demonstrated that a sequence-directed bend could substitute for a protein induced bend (via IHF) in the integration process of $\lambda$. Similarly, our results show that the cAMP-CRP complex could be efficiently replaced by curved sequences in the activation of two overlapping promoters.

\section{Materials and methods}

Constructions of hybrid promoters and nucleic acid techniques Sequences II, III and IV listed in Figure $1 \mathrm{~b}$ are EcoRI - HindIII fragments extracted from plasmids pK1A108, pK4A108 and pK5/6A216 described by S.Diekmann (1987 and personal communication). The sequence $\mathrm{V}$ corresponds to the EcoRI-HindIII fragment extracted from plasmid pCB5162 (gift from Richard Losick) which contains the A/T rich upstream region of promoter SpoVG cloned in pBR322 (Banner et al., 1983). The sequence I has been generated by joining a blunt-ended BstEII linker to the HhaI-BstNI fragment of the lac promoter sequence (Douc-Rasy et al., 1989). It contains the quasi-palindromic CRP binding site. All five fragments were blunt-ended with the Klenow fragment.

The vector plasmids pAA187 8807 and pAA187 420 are described in Busby et al. (1983). Each bears an EcoRI-HindIII fragment 72 and 75 bp long respectively, containing the deleted gal promoters which control the expression of the lac operon. Their unique SmaI site served for the blunt end ligations of the five fragments listed in Figure $1 \mathrm{~b}$. The ligation products were transfected in M182recA. Selective growths were performed on MacConkey lactose agar plates supplemented with $100 \mu \mathrm{g} / \mathrm{ml}$ ampicillin. On this medium the original plasmids give rise to $\mathrm{Lac}^{-}$white colonies while plasmids having recovered a functional promoter give red $\mathrm{Lac}^{+}$ colonies. Minilysates from these colonies have been examined for the presence of insertions by measuring the apparent size of the EcoRI-HindIII fragments. Orientation of the insertions have been determined by end labelling the plasmids at the EcoRI site and looking for the length of the labelled fragments generated by a convenient secondary restriction ( $B a n I$ for sequence I, AluI for inserts II, III and IV, and DraI for the sequence V). Selected constructs were sequenced according to the dideoxy procedure using MMLV reverse transcriptase or the Sequenase kit provided by US Biochemicals Corporation.

\section{Strains}

Table $\mathrm{V}$ lists the strains which have been used in this study.

Strain M182 was a kind gift from S.Busby. P1 co-transduction of $\Delta c y a 854$ with ilv:: $\operatorname{Tn} 5$, selecting for kanamycin resistance and cya ${ }^{-}$character led to strain M182 Acya (the donor strain is described in Ebright et al., 1984).

The gene coding for topoisomerase $\mathrm{I}$ is located between $\mathrm{pyrF}$ and the $t r p$ EDCBA operon. M182 and M182 $c$ cya were then rendered $t r p^{-}$and $\mathrm{Tc}^{\mathrm{R}}$ by insertion of a $\mathrm{Tn} l O$ transposon in the $t r p$ operon. P1 transduction from KZ43 (pyrF) and KZ44 (pyrF top 10) (both gifts from J.Wang) and selection for the $\operatorname{trp}^{+}-\mathrm{pyr}^{-}$characters in derivatives of strain M182 led 
to strains $\mathrm{T} 13, \mathrm{~T} 14$ and $\mathrm{T} 23$. The top ${ }^{-}$character of strain $\mathrm{T} 23$ was checked by a published procedure (Sternglanz et al., 1981).

P1 transduction from strain KD112 (JTT1 gyrB226 tnaA:: $\mathrm{Tn} 10\left(\mathrm{Tc}^{\mathrm{R}}\right)$, a gift from K.Drlica) into strain $\mathrm{T} 13$ and selection for the $\mathrm{Tc}^{\mathrm{R}}$ character led to strain $\mathrm{T} 33$. The $\mathrm{gyr}^{-}$character of this strain was verified by its enhanced sensitivity to $50 \mu \mathrm{g} / \mathrm{ml}$ novobiocin relative to strain T13. To prevent possible recombination events between the polymerized motifs (1A10, $4 \mathrm{~A} 10,5 \mathrm{~A} / 6 \mathrm{~A}$ ), strain M182 and strains T13, T23, T33, T14 were all rendered recA by mating with strains GC2226 and MCL30 respectively. The recA character of the resulting strains was corroborated by their increased sensitivity to UV light.

Strain 02014 (hip) was generously donated by R.Weisberg.

\section{$\beta$-Galactosidase assay}

$50 \mu \mathrm{l}$ of an overnight culture in rich medium were used to inoculate $5 \mathrm{ml}$ of M63B1 medium supplemented with fructose $0.5 \%(\mathrm{w} / \mathrm{v})$, casamino acids $0.5 \%(\mathrm{w} / \mathrm{v})$, uracil $(50 \mu \mathrm{g} / \mathrm{ml})(+50 \mu \mathrm{g} / \mathrm{ml}$ kanamycin for T14recA). Cells were grown to $\mathrm{OD}_{600}=0.3-0.4$ and the assay performed as in Miller (1972) using $\mathrm{CHCl}_{3}, 0.1 \%$ SDS to permeate the cells. The linearity of the assay with the cell density and the time of reaction with ONPG has been verified. The results indicated represent the average of at least three separate sets of experiments, each one with duplicate samples, the error on the assay being $<15 \%$.

\section{mRNA analysis}

Total RNA was extracted according to a published procedure (Aiba $e t$ al. 1981 ) and quantified by its UV spectrum. A labelled probe (16mer, 1 pmol) corresponding to the beginning of the coding region was hybridized to $0.5 \mu \mathrm{g}$ total RNA in $0.4 \mathrm{M} \mathrm{KCl}$ by slowly cooling down from 90 to $20^{\circ} \mathrm{C}$. Following extension by $100 \mathrm{U}$ of MMLV reverse transcriptase in $50 \mathrm{mM}$ Tris $\mathrm{pH} 7.6,3 \mathrm{mM} \mathrm{MgCl}, 130 \mathrm{mM} \mathrm{KCl}, 10 \mathrm{mM}$ dithiothreitol (DDT), $0.5 \mathrm{mM}$ of each dNTP for $1 \mathrm{~h}$ at $37^{\circ} \mathrm{C}$, the products were resolved by PAGE ( $10 \%$ acrylamide, $7 \mathrm{M}$ urea). Under these conditions, the intensity of the extended chain was found to be proportional to the amount of total RNA used in the hybridization. The major two bands observed were shown to correspond to a $\mathrm{Pl}$ or a $\mathrm{P} 2$ start by using dideoxy-sequencing reactions as markers.

\section{In vitro transcription}

Plasmids $4 \mathrm{~A}-\Delta 807^{\prime}$ and $1 \mathrm{~A}-\Delta 807$ were prepared on a large scale and purified using the protocol and the pZ523 columns from 5 Prime $\rightarrow 3$ Prime, Inc.

Escherichia coli RNA polymerase was prepared as described (Lowe et al., 1979). $5 \mathrm{nM}$ plasmid DNA was preincubated with $100 \mathrm{nM}$ RNA polymerase

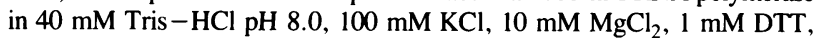
$100 \mu \mathrm{g} / \mathrm{ml} \mathrm{BSA}$ for $30 \mathrm{~min}$ at 37 or $16^{\circ} \mathrm{C}$. Transcription was initiated by the addition of XTPs $\left(0.5 \mathrm{mM}\right.$ each). The reaction was stopped at $90^{\circ} \mathrm{C}$ after 10 or $30 \mathrm{~min}$. The origin and amount of transcripts were determined by the primer extension technique described in the preceding paragraph. IHF protein was kindly provided by H.Nash.

\section{DNA binding assays}

$\mathrm{H} 1$ and $\mathrm{HU}$ were generous gifts from Drs S.Rimsky and A.Spassky, and E.Bonnefoy and J.Rouvière-Yaniv respectively. Plasmids pK4A108 and pK1A108 were cut with EcoRI and $3^{\prime}$ end-labelled with $\left[\alpha{ }^{32} \mathrm{P}\right] \mathrm{dATP}$ using Klenow fragment and then cut by HaeIII restriction enzyme. The $256 \mathrm{bp}$ EcoRI-HaeIII fragments were purified on a 5\% polyacrylamide gel and subsequently cut by HindIII restriction enzyme, to give the $113 \mathrm{bp}$ EcoRI-HindIII fragments, named $4 \mathrm{~A}$ and $1 \mathrm{~A}$ respectively.

For binding experiments $4 \mu \mathrm{l}$ of each $113 \mathrm{bp}$ fragment $\left(5 \times 10^{-10} \mathrm{M}\right)$ were gently mixed with $4 \mu$ l of the diluted protein in $20 \mathrm{mM}$ Tris $-\mathrm{HCl}$ pH 7.9, $0.1 \mathrm{mM}$ EDTA, $50 \mathrm{mM} \mathrm{NaCl}$ and $100 \mu \mathrm{g} / \mathrm{ml} \mathrm{BSA}$. After $1 \mathrm{~h}$ incubation at room temperature, $1.5 \mu \mathrm{l}$ of $50 \%$ glycerol with $0.01 \%$ xylenecyanol blue in the same buffer was added and the mixture directly loaded on a $7.5 \%$ polyacrylamide gel $(75 \times 75 \times 0.8 \mathrm{~mm})$, run at $12 \mathrm{~V} / \mathrm{cm}$ in $45 \mathrm{mM}$ Tris - borate, $1.25 \mathrm{mM}$ EDTA until the dye migrated $4 \mathrm{~cm}$. For RNA polymerase binding, the mixture was incubated for $30 \mathrm{~min}$ at $37^{\circ} \mathrm{C}$, then $2 \mu \mathrm{l}$ of the glycerol buffer dye containing $120 \mu \mathrm{M}$ M13 single-stranded DNA was added to the sample before loading on a $4 \%$ polyacrylamide gel.

\section{Acknowledgements}

We thank Nathalie Sassoon and Pascal Roux for technical assistance, and Horace Drew for constant exchange of information and stimulating discussions. We are also very obliged to Cécile Wandersman for her advice on strain constructions and Olivier Raibaud for critical readings of this article. This work was carried out in a laboratory associated to the Centre National de la Recherche Scientifique and supported also by grants from the Ministère de la Recherche et de l'Enseignement Supérieur and from the Fondation de la Recherche Médicale. L.B. is a recipient of a fellowship from the Fondation pour la Formation par la Recherche à l'Interface Chimie-Biologie. S.D. thanks the EMBO for a short-term fellowship.

\section{References}

Aiba,H., Adhya,S. and de Crombrugghe,B. (1981) J. Biol. Chem., 256, $11905-11910$

Banner,C.D.B., Moran,C.P.,Jr and Losick,R. (1983) J. Mol. Biol., 168 , $351-365$.

Bauer,B.F., Kar,E.G., Elford,R.M. and Holmes,W.M. (1988) Gene, 63, $123-134$.

Bossi,L. and Smith,D.M. (1984) Cell, 39, 643-652.

Brahms,J., Dargouge, O., Brahms,S. and Ohara-Vagner,V. (1985) J. Mol. Biol., 181, 455-465.

Busby,S. and Buc,H. (1987) Microb. Sci., 4, 371-375.

Busby,S., Kotlarz,D. and Buc,H. (1983) J. Mol. Biol., 167, 259-274.

Busby,S., Spassky,A. and Chan,B. (1987) Gene, 53, 145-152.

Casadaban,M.J. and Cohen,S.N. (1979) J. Mol. Biol., 138, 179-207.

Chan,B. and Busby,S. (1989) Gene, in press.

Chen,W., Tabor,S. and Struhl,K. (1987) Cell, 50, 1047-1055.

de Crombrugghe,B., Busby,S. and Buc,H. (1984) In Goldberger,R.F. and Yamamoto,K.R. (eds), Biological Regulation and Development. Plenum Publ. Corp., New York, Vol. 3B, pp. 129-167.

Deuschle,U., Kammerer,W., Gentz,R. and Bujard,H. (1986) EMBO J., 5, 2287-2294.

Diekmann,S. (1987) Nucleic Acids Res., 15, 247-265.

Douc-Rasy,S., Kolb,A. and Prunell,A. (1989) Nucleic Acids Res., 17, $5173-5189$.

Dreyfus,M., Kotlarz,D. and Busby,S. (1985) J. Mol. Biol., 186, 117-128.

Drlica,K. and Rouvière-Yaniv,J. (1987) Microb. Rev., 51, 301-319.

Drlica,K., Pruss,G., Manes,S. and Chevalier,S. (1986) In Gualerzi,C.O. and Pon,C.L. (eds), Bacterial Chromatin. Springer-Verlag, Berlin, pp. $52-63$.

Ebright,R., Cossart,P., Gicquel-Sanzey,B. and Beckwith,J. (1984) Nature, 311, 232-235.

Galas,D.J., Eggert,M. and Waterman,M.S. (1985) J. Mol. Biol., 186, $117-128$.

Goodman,S.D. and Nash,H.A. (1989) Nature, 341, $251-254$.

Gourse,R.L., de Boer,H.A. and Nomura,M. (1986) Cell, 44, 197-205. Hawley,D.K. and McClure,W.R. (1983) Nucleic Acids Res., 11, $2237-2255$

Horwitz,M. and Loeb,L. (1988) J. Biol. Chem., 263, 14724-14731.

Jacquet,M.-A., and Ehrlich,R. (1985) Biochimie, 67, 987-997.

Kolb,A., Spassky,A., Chapon,C., Blazy,B. and Buc,H. (1983) Nucleic Acids Res., 11, 7833-7852.

Koo,H.-S. and Crothers,D.M. (1988) Proc. Natl. Acad. Sci. USA, 85 , $1763-1767$.

Koo,H.-S., Wu,H.-M. and Crothers,D.M. (1986) Nature, 320, 501-506. Lamond,A.I. and Travers,A.A. (1983) Nature, 305, 2003-2009.

Lorence,M.C. and Rupert,C.S. (1983) J. Bacteriol., 156, 458-459.

Lowe,P.A., Hager,D.A. and Burgess,R.R. (1979) Biochemistry, 18 $1344-1352$.

Mandecki,W. and Caruthers,M. (1984) Gene, 31, 263-267.

McAllister,C.F. and Achberger,E.C. (1988) J. Biol. Chem., 263, $11743-11749$.

McAllister,C.F. and Achberger,E.C. (1989) J. Biol. Chem., 264, $10451-10456$

Miller,J.H. (1972) In Experiments in Molecular Genetics. Cold Spring Harbor Laboratory Press, Cold Spring Harbor, NY, pp. 352-355.

Plaskon,R.R. and Wartell,R.M. (1987) Nucleic Acids Res., 15, 785-796. Queen,C. and Rosenberg,M. (1981) Cell, 25, 241-249.

Russell,D., Smith,M., Cox,D., Williamson,V. and Young,E. (1983) Nature, 304, 652-654.

Spassky,A., Rimsky,S., Garreau,H. and Buc,H. (1984) Nucleic Acids Res. $12,5321-5340$.

Sternglanz,R., diNardo,S., Voelkel,K., Nishimura,Y., Hirota,Y., Becherer,K., Zumstein,L. and Wang,J. (1981) Proc. Natl. Acad. Sci. USA, 78, 2747-2751.

Straney,D., Straney,S. and Crothers,D. (1989) J. Mol. Biol., 206, 41-57. Ulanovsky,L., Bodner,M., Trifonov,E. and Choder,M. (1986) Proc. Natl. Acad. Sci. USA, 83, 862-866.

Wandersman,C., Moreno,F. and Schwartz,M. (1980) J. Bacteriol., 143, $1374-1383$.

Wu,H.-K. and Crothers,D.M. (1984) Nature, 308, 509-513.

Received on July 31, 1989; revised on September 11, 1989 